\title{
Artigo
}

Resumo

Este artigo visa a fazer uma revisão bibliográfica de autores que estudam o autismo numa perspectiva lacaniana, dando ênfase à noção do inconsciente estruturado como linguagem, bem como a aspectos fundamentais para pensar a constituição do sujeito e uma possivel falha nesse processo, que ocorreria em crianças autistas, como a inscrição significante, a relação sujeito-Outro e os registros pulsionais, apontando, como primazia, o circuito da pulsão invocante.

Descritores: autismo; psicanálise; pulsão invocante; constituição do sujeito; vo:

\section{AUTISMO: UM MODO \\ DE APRESENTAÇÃO DO SUJEITO NA ESTRUTURA DE LINGUAGEM}

\author{
Marcela Maria de Paiva Azevedo \\ Roseane Freitas Nicolau
}

\section{Introdução}

Pensar a constituição do sujeito nos preceitos da psicanálise lacaniana implica retomar um percurso singular, entretanto universal, a ser atravessado, e que envolve um processo relacionado com a inscrição no simbólico, a instauração dos circuitos pulsionais, a articulação ao campo do Outro e a assunção de um lugar no discurso. O autismo, por esse ângulo, aponta para uma questão

- Psicóloga da Unidade Municipal de Saúde do Guamá, vinculada à Secretaria Municipal de Saúde do Município de Belém,

PA. Mestre em Psicologia pela Universidade Federal do Pará, Belém, PA, Brasil.

- - Psicanalista. Membro da Escola de Psicanálise Letra Freudiana. Professora Associada da Faculdade de Psicologia e do Programa de Pós-Graduação em Psicologia da Universidade Federal do Pará, Belém, PA, Brasil. 
extremamente instigante, pois algo nesse percurso falha, evidenciando outro modo de funcionar na estrutura da língua. Em contraponto a essa perspectiva, a psiquiatria positivista contemporânea - guiada pelos pressupostos indicados nos Manuais Diagnósticos e Estatísticos de Transtornos Mentais (DSM), que a partir da terceira versão rompem com o ecletismo de saberes em prol de uma abordagem que prioriza estudos epidemiológicos e dados estatísticos para atingir uma suposta objetividade (Bernardino, 2011) - concebe o autismo como uma síndrome, cuja particularidade evidencia uma lógica que elimina qualquer dimensão de aquisições adaptativas e caracteriza-se por déficits significativos em várias áreas do desenvolvimento, especialmente na comunicação.

Tendo em vista que uma falha nos processos mencionados implica num peculiar modo de operar com a linguagem, um importante grupo de pesquisadores contemporâneos, no campo da psicanálise lacaniana e que se interessa pelo trabalho com crianças autistas, tem feito reflexões constantes e que possibilitam identificar o ponto de fracasso em que algo nessas operações não se engendra, permitindo alcançar uma direção possível ao tratamento. Dentre eles, destacamos Marie-Christine Laznik (2004; Laznik, Maestro, Muratori, Parlato-Oliveira, 2006), Maria Cristina Kupfer (2000), Alfredo Jerusalinsky (2012) e Inês Catão (2009).

Dessa forma, nosso objetivo aqui é percorrer as contribuições teóricas de vários pesquisadores contemporâneos que apoiam suas elaborações nos argumentos que Jacques Lacan trouxe à teoria freudiana, sobretudo no que diz respeito ao funcionamento psíquico mediado pela linguagem, bem como apontar alguns aspectos que julgamos primordiais para pensar essa clínica, como a possibilidade da vOz se fazer objeto da pulsão. Para tanto, partiremos do seguinte questionamento: o que falha na constituição do sujeito autista? Ou ainda: qual é o lugar do autista na estrutura da linguagem?

\section{Autismo: uma falha na constituição subjetiva}

No artigo "Do fracasso da instauração da imagem do corpo ao fracasso da instauração do circuito pulsional: quando a alienação faz falta”, Laznik (2004), ao pensar a falha na constituição do sujeito autista, fala de duas operações de causação do sujeito - alienação e separação - para distinguir o autismo das psicoses. Nesse trabalho, a autora aborda a importância do olhar do Outro na constituição do eu, na medida em que este funda sua consistência imaginária. Ela também aborda o fracasso na operação da alienação como um fracasso na instauração do circuito pulsional. $\mathrm{O}$ momento da alienação diz respeito justamente ao surgimento de um novo sujeito, alinhado ao Outro, que ocorre no terceiro tempo do circuito, 
mas que, nas crianças diagnosticadas com autismo, não se observa.

Kupfer (2000) atribui a causa da síndrome a uma falha na função materna, comparando-a à psicose, na qual haveria também uma falha, mas na função paterna. Ou seja, na psicose a criança se aliena, mas não separa, enquanto no autismo a criança não chega a se alienar:

Mas a razão última para o autismo continua sendo a falha na função materna. A partir do colapso da função materna, muitos poderão ser os efeitos. Poderá ocorrer uma inoperância radical da função e do desejo maternos, o que resultará em uma ausência de imagem do corpo, já que o principal dessa função é a construção de um mapa libidinal do corpo (Kupfer, 2000, p. 91).

Porém, ainda que se atribua às funções materna e paterna a diferença entre autismo e psicose, Kupfer (2000) deixa claro que a falha na função materna terá, como consequência, o fracasso de um mapa libidinal para o corpo, o que remete ao circuito pulsional.

A referência aos circuitos pulsionais versa também sobre o entendimento de como o sujeito se articula ao campo da linguagem, na medida em que o corpo-organismo é desnaturalizado em prol de um corpo que funciona sob a égide do simbólico, cuja articulação só é possível a partir do funcionamento dos circuitos. Alfredo Jerusalinsky (2012) menciona o fracasso da entrada na linguagem observado nas crianças diagnosticadas com autismo, nas quais a prevalência de automatismos funciona como resistência à entrada do Outro:

O autismo consiste fundamentalmente no fracasso na construção dessas redes de linguagem - fornecedoras de saber sobre o mundo e as pessoas - e na prevalência de automatismos que, disparados de modo puro e espontâneo, carecem de qualquer valor relacional e fazem resistência à entrada do outro no mundo da criança, e, consequentemente, na entrada dela no mundo familiar e social (Jerusalinsky, 2012, p. 60).

Segundo o autor, para que se opere a estrutura da linguagem é preciso que haja um ponto de encontro e de identificação entre a criança e o Outro primordial, que, em geral, está encarnado na figura materna ou do cuidador. Para falar sobre essas identificações, ele faz referência ao estádio do espelho, que diz respeito, segundo Lacan (1949/1998), às transformações que são produzidas no sujeito quando ele assume uma imagem. Essa imagem é especular ao que o olhar do outro vê - logo, esse estágio, que transcende o desenvolvimento, versa sobre a possibilidade de se reconhecer no Outro. Esse intercâmbio especular, mediado por traços linguísticos, transforma o reconhecimento entre a criança e seu Outro, e, nesse sentido, Jerusalinsky (2012) observa que há um fracasso nessa "função de reconhecimento", que seria a porta de entrada ao mundo propriamente humano. Como consequência desse fracasso, a operação de entrada no campo da 
linguagem falha também, e é essa característica que, invariavelmente, aparece em todos os casos de autismo.

Observa-se que os autores citados entendem o autismo como distinto da psicose. Jerusalinsky (2012), de forma bastante polêmica, chega, inclusive, a definir uma quarta estrutura, que se distinguiria das demais por se tratar da estrutura da exclusão do campo do Outro e do registro da linguagem. O autor afirma: "a prevalência dos automatismos cria um mecanismo de exclusão da criança a respeito da linguagem" (Jerusalinsky, 2012, p. 65). É necessário destacar, entretanto, que essa concepção é criticada por muitos pesquisadores que abordam a temática no campo da psicanálise lacaniana contemporânea.

Bastos (2012) indica que, de modo geral, a distinção entre essas possibilidades de estrutura se resume em situar a posição da criança em relação ao Outro: na psicose haveria uma alienação ao Outro, sem haver, contudo, a separação; logo, os psicóticos sofreriam com uma presença excessiva do Outro. Já nas crianças autistas, o processo de alienação não teria sequer chegado a ocorrer, havendo uma falha, portanto, num período lógico anterior à falha que é observada na psicose; portanto, elas sofreriam pela falta de inscrição do Outro.

Rocha (2009) mostra que, nos textos de psicanalistas lacanianos, essa perspectiva que concebe o Outro ausente no autista parece comum. Essas concepções teriam se apoiado nas teorizações, sobretudo de Laznik, e repercutem na concepção do autista com falhas nas dimensões simbólica (falta de significantes que demarquem a criança), real (não instalação dos circuitos pulsionais) e imaginária (não instauração da imagem especular). O autor, contudo, discute que afirmar que os autistas estão excluídos do campo do Outro é pensar que ou os autistas são uma subjetivação sem pulsão e sem Outro, ou que inexiste subjetivação no autismo - o que é demasiado complicado, pois é como recusar neles uma dimensão necessária à humanidade.

Não é do escopo deste artigo esmiuçar o que cada uma dessas posições defende, mas, diante do paradoxo que o autismo abarca por questionar a inscrição na linguagem ou, mais precisamente, a humanidade presente nas pessoas diagnosticadas, já que partimos da concepção de que o humano é efeito da linguagem, é fundamental nos posicionarmos. Logo, entendemos as manifestações linguísticas observadas no autismo, bem como a recusa de manifestar-se, como índice de presença de linguagem, ainda que esta não sirva à comunicação. Vorcaro e Lucero 
(2010) afirmam que, ao tapar os ouvidos, a criança autista está no campo da linguagem, pois dela se defende. As autoras esclarecem:

Efetivamente, se localizamos o sujeito na definição magistral de Lacan de que um significante representa um Sujeito para outro significante, ou seja, $(\mathrm{S} 1 \rightarrow \$ \rightarrow \mathrm{S} 2)$, há sujeito em qualquer concatenação significante. Assim sendo, desde que haja uma demanda e uma resposta, mesmo que essa se reduza à recusa associada a um olhar endereçado por um desvio daquele que o recebe, temos a presença, sempre evanescente, do sujeito que concatenou olhar e desvio mesmo que para operar sua descontinuidade (Vorcaro \& Lucero, 2010, p. 148-149).

Nesse sentido, as autoras defendem a ideia de que o lugar do sujeito, como efeito de linguagem, surge a partir dos significantes advindos do Outro; contudo, nos casos de autismo, esse lugar, no qual o sujeito é chamado a funcionar, fica paralisado. Lacan (1964/2008) afirma: "quando não há intervalo entre o S1 e o S2, ... a primeira dupla de significantes se solidifica" (p. 231). Porém, ainda que paralisada, a intrusão na linguagem faz marca no sujeito, sem que ele possa, entretanto, brincar com ela ou ordená-la numa cadeia significante (Vorcaro \& Lucero, 2010).

Tendo em vista esses aspectos, é necessário refletir sobre a questão da linguagem na constituição do sujeito, já que este surge como efeito da língua e é com ela que deve operar para fazer laços sociais. 


\section{Por um sujeito como efeito da linguagem}

Desde as primeiras formulações da psicanálise, Freud apostou nos poderes da palavra e na cura pela fala. As origens das manifestações sintomáticas histéricas não eram passíveis de ser compreendidas organicamente, e por esse motivo foi preciso estender essas concepções para a possibilidade de haver uma instância psíquica inconsciente, cujas inscrições não poderiam ser tratadas por um viés biológico ou anatômico. Com Freud, aprendemos que existe uma dimensão psíquica para a linguagem, e que é pela palavra que o inconsciente se articula ao corpo. Na "Carta 52 a Fliess" (1895/1990) e em A interpretação dos sonhos (1900/2001), Freud mostra que as experiências vivenciadas pelos falantes são registradas a partir de signos, cujo caráter principal é a separação entre a representação mental e a coisa.

A condição humana determina que nossa existência se defina muito mais no terreno das representações possíveis de se dar a determinado fato do que na corporeidade deles. No retorno que Lacan faz a Freud, ele tem a possibilidade, com o apoio da linguística estrutural, de situar a estruturação do inconsciente a partir de um encadeamento significante, que produz um saber, no qual o sujeito está localizado. Isso remete à noção de sujeito barrado (\$), introduzida por Lacan, que diz respeito justamente à barreira que a linguagem representa, em que o sujeito em si jamais poderá advir, a não ser pela articulação significante. Lacan (1960/1998), no texto "Posição do inconsciente", assinala:

O registro do significante institui-se pelo fato de um significante representar um sujeito para outro significante. Essa é a estrutura, sonho, lapso e chiste de todas as formações do inconsciente. E é também a que explica a divisão originária do sujeito. Produzindo-se o significante no lugar do Outro ainda não discernido, ele faz surgir ali o sujeito do ser que ainda não possui fala, mas ao preço de cristalizá-lo (p. 854).

Ou seja, antes mesmo de poder falar, o sujeito já é introduzido na dinâmica da língua, o que o furta da mera corporeidade das experiências e the entrega esse registro cristalizante, o qual possibilita que ele se torne falante ao construir um saber sobre si e ao assumir um lugar no discurso ao qual possa se referir. Mas, para que o sujeito seja introduzido e causado pela linguagem, é preciso que haja a transmissão dela. $\mathrm{Na}$ continuidade do texto, Lacan define o 
mecanismo da alienação do sujeito à língua, afirmando que essa alienação não se caracteriza pelo fato de o início da operação de divisão do sujeito ocorrer no Outro que se encarrega da transmissão, mas sim na própria divisão do sujeito em sua causa. A participação do Outro traduz-se apenas na impossibilidade de qualquer sujeito ser causa de si mesmo. Mas o que o causa então?

O efeito de linguagem é a causa introduzida no sujeito. Por esse feito, ele não é causa de si mesmo, mas traz em si o germe da causa que o cinde. Pois sua causa é o significante sem o qual não haveria nenhum sujeito no real. Mas esse sujeito é o que o significante representa, e este não pode representar nada senão para um outro significante: ao que se reduz, por conseguinte, o sujeito que escuta. Com o sujeito, portanto, não se fala. Isso fala dele e é aí que ele se apreende (Lacan, 1960/1998, p. 849).

Estamos falando de um aspecto do momento originário da constituição do sujeito pela linguagem, momento esse que parece falhar nas crianças que manifestam sintomatologias autísticas. Em 1975, na "Conferência de Genebra sobre o sintoma”, Lacan (1998) sugere que os analistas escutem mais os autistas e surpreende ao afirmar que eles são indivíduos preferencialmente verbosos. A surpresa deve-se ao fato de que a palavra "verboso" remete a comunicação; mas se o autismo é uma síndrome caracterizada por déficits na comunicação, como seriam esses sujeitos verbosos? Maleval (2007) explica que, no autismo, não se trata de falar ou não falar, mas do quanto o sujeito está implicado em sua fala, ou seja, o quanto seu dizer fala sobre si. Logo, a verborragia autista é uma manifestação cheia de palavras, na qual o sujeito está ausente. Rodriguez (1999) mostra que, independente de como a sintomatologia se apresenta, há uma marca que é indelével nessa síndrome: o autismo carrega a ferida da má sucessão na pragmática do discurso; logo, quer seja mudo, ecolálico ou verborrágico, a fala não diz sobre si. Mas o que faz o sujeito se inscrever no registro simbólico e se utilizar da linguagem para a enunciação?

Maleval (2007), ao discorrer sobre a falta de enunciação no falar autista, afirma que, neles, o que carece é a voz enquanto objeto pulsional; logo, não é a sonoridade da voz que a caracteriza enquanto pulsão, mas justamente a manifestação do ser do sujeito na vocalização. Essa afirmação evidencia a importância da voz pulsionalizada para a assunção de um lugar no discurso. Contudo, o que promove a voz ao estatuto de pulsão?

Vivès (2012) cita o papel da pulsão invocante, com sua estreita ligação com o significante e com a fala, nesse processo. A voz, portanto, seria objeto da pulsão e, nesse sentido, suporte de um enunciado. Porge (2014) caracteriza a voz como o que sustenta a passagem ao significante, mas mostra, também, que, ao ser batizada como objeto a por Lacan, 
a voz é estruturada pelo corte. Ora, isso faz referência à inscrição do sujeito no mundo simbólico, pois, quando se torna barrado pela linguagem, passando a ser representado pelo significante, há uma impossibilidade de ele se apreender por completo, já que há um furo no Outro, uma carência de significantes que o represente, denotando que algo foi perdido nessa inscrição. $\mathrm{Na}$ divisão do sujeito pelo Outro, o sujeito divido (\$) é o quociente, mas, como resto, tem-se o objeto $a$, do qual a voz é um representante, junto do seio, das fezes e do olhar (Porge, 2014).

No texto intitulado "Os instintos e seus destinos" (1915/2010), no qual foi definido o circuito pulsional enquanto condição para satisfação da pulsão, Freud refere-se aos pares sadismo-masoquismo e exibicionismo-voyeurismo a fim de falar de três tempos no circuito. A respeito do primeiro par, o autor fala da transformação da atividade em passividade: no primeiro momento, prevalece o sadismo enquanto prática violenta e de exercício de poder sobre uma pessoa, que é tratada como objeto (atividade); no segundo momento, ocorre o abandono desse objeto, que é substituído por si mesmo, com a consequente transformação da atividade em passividade; e no terceiro momento, ocorre a busca por outra pessoa, mas, em razão da mudança de atividade para passividade, o sujeito assume o papel de objeto passivo (masoquismo). Em relação ao último par e à pulsão escópica, Freud detalha:

Resultados diversos, e mais simples, são proporcionados pela investigação de outro par de opostos, o dos instintos que têm por meta olhar e mostrar-se. (Voyeur e exibicionista, na linguagem das perversões.) Neste caso, pode-se estabelecer os mesmos estágios do anterior: a) olhar como atividade dirigida a um outro objeto; b) o abandono do objeto, a volta do instinto de olhar para uma parte do próprio corpo, e com isso a reversão em passividade e a constituição de uma nova meta: ser olhado; c) a introdução de um novo sujeito, ao qual o indivíduo se mostra, para ser olhado por ele (Freud, 1915/2010, p. 67-68, grifo nosso).

Ao discutir o circuito pulsional, Lacan (1964/2008) também destaca: "o que é fundamental, no nível de cada pulsão, é o vaivém em que ela se estrutura" (p. 175). Ou seja, a satisfação da pulsão não se engendra no encontro de uma finalidade específica, e sim no retorno ao próprio circuito, que não cessa de circular e de contornar um objeto perdido. Em outros termos, a satisfação está no fato de perfazer um giro, de contornar a experiência de prazer em busca de algo que não se sabe. O próprio contorno e a constante 
ressignificação dessa experiência é o que dá o toque circular do circuito pulsional que jamais se encerra.

Sobre o surgimento de um novo sujeito no terceiro tempo, Catão (2009) mostra que a novidade é a alienação ao Outro e destaca a função das figuras parentais nesse processo - afinal, é em relação aos pais que a criança constitui seu desejo. Quando Lacan grafa "Outro" com maiúscula, pretende marcar um lugar situado mais além em relação ao da identificação especular com os pais: "O Outro assim grafado aponta para uma ordem que, exterior e anterior ao sujeito, e a despeito deste, o determina" (Catão, 2009, p. 140). Segundo a autora, no limite, o Outro se confunde com a ordem da linguagem, "é no Outro da linguagem que o sujeito vai procurar situar-se, procura incessante, pois nenhum significante é suficiente para defini-lo" (Catão, 2009, p. 141). Nesse sentido, o novo sujeito é sujeito em articulação com o Outro da linguagem, cujo laço é necessário para que ele possa se tornar falante e desejante.

Em consonância com os argumentos expostos, Vorcaro (2011) afirma que "a estruturação do sujeito é o percurso desde o momento em que um adulto atribui significação para o organismo do neonato, até o momento em que ela mesma, a criança, possa evocar e referir-se à sua significância num laço social" (p. 228), ou seja, é sempre a posição do sujeito na língua que define o valor de seus atos e sua 
posição no conjunto social. Logo, se uma criança não consegue ascender a uma posição no discurso, como irá ocupar um lugar de sujeito? $\mathrm{O}$ autismo escancara, a partir dos distúrbios linguísticos, os entraves no processo de entrada e a assunção desse lugar, tanto quanto mostra, na perspectiva abordada, que o sujeito com o qual estamos lidando não é o mesmo concebido pela etiologia psiquiátrica, e sim o sujeito da cadeia significante, efeito da linguagem.

\section{Autismo: em busca de uma voz}

Maleval (2007) destaca que "o autista é um sujeito que se caracteriza por não ter incorporado o objeto vocal que suporta a identificação primordial, resultando disso uma carência de S1 em sua função representativa" (p. 69). Segundo o autor, é especificidade do objeto voz comandar a identificação primordial, pois é a voz no campo do Outro que possibilita a ligação ao Outro; logo, se esse enodamento não se produz, o S1 não representa o sujeito para outros significantes. A linguagem do autista não é investida de gozo vocal, logo, sua fala não serve à comunicação.

Soler (2007), ao falar sobre autismo, destaca como características da síndrome: (1) a perseguição, ou mesmo invasão, pelos signos de presença do Outro, sobretudo pelos objetos voz e olhar; (2) a referência ao fato de que, a princípio, as crianças parecem ser surdas ou apresentam distúrbios visuais, como se aparentemente anulassem o Outro, mas que a autora destaca como uma característica que é "o oposto de uma anulação do Outro"; (3) a recusa da dimensão de apelo, e já que é pela voz e pelo olhar que o Outro chama, essas crianças também não entram na demanda, não suportam a intimação do Outro; e (4) a dificuldade de se separar das figuras que encarnam o Outro. Essas propriedades, observadas na síndrome, denotam uma importância primordial ao objeto voz e ao objeto olhar na dimensão da constituição do sujeito, mas, para além disso, a relação com a voz e com o olhar se torna peculiar em função de se constituírem como objeto $a$, uma das grandes invenções da teoria lacaniana, que faz referência ao objeto caído, cortado pela operação da linguagem (Soler, 2007). No autismo, parece que esses objetos não se perdem, ou não se convertem como função, e é por isso que a relação do sujeito com eles é tão caótica.

Nominé (2012) afirma que é preciso separar do autista o objeto voz e o objeto olhar, para que estes não o invadam. É a invasão da voz que impede esses sujeitos de falar. Mas o que possibilitaria que alguns, ainda que, de forma automatizada e maquinada, emitam sons? Segundo o autor, isso denota que esses "verbosos" conseguiram renunciar, em parte, ao gozo autístico da voz, mas 
não por completo. Renunciar a esse gozo supõe admitir o equívoco, o mal entendido, a maleabilidade do significante, que se desenvolve no vazio deixado pela queda do objeto.

Retomamos Soler (2007), que, ao falar sobre o Outro no autismo, afirma que falta um lugar vazio, onde o sujeito poderia alojar-se. É como se ele ficasse aquém do limiar de qualquer simbolização. Ela compara o autismo à paranoia e mostra que, nesta, o Outro se inscreve como barrado, enquanto, no autismo, o Outro continua puramente real, ou seja, as crianças autistas permanecem como puro significado do Outro, sendo sujeitos, mas não enunciadores de um discurso. A autora caracteriza, ainda, o autismo como uma doença da libido, na medida em que a linguagem que causa o sujeito age também sobre seu corpo, o que remete ao funcionamento pulsional.

Esses argumentos são de fundamental importância para este trabalho, pois coloca o olhar e, sobretudo, a voz num lugar privilegiado para a compreensão das manifestações linguísticas que são observadas no autismo. Sabe-se que Lacan promoveu esses dois objetos ao mesmo nível dos objetos pulsionais freudianos, que são o objeto oral (seio), o anal (fezes) e o fálico (pênis), mas, além disso, também os legou ao estatuto de objeto $a .{ }^{1} \mathrm{~N}^{\prime} O$ seminário 11 , Lacan se propõe a desenvolver a noção do objeto olhar, mas o recorte da voz, em sua dimensão constitutiva, não é aprofundado. Até então, fica claro que a linguagem tem um papel primordial na constituição do sujeito e no processo pelo qual ele assume um lugar no discurso; entretanto, algo deve acontecer para que esse ato ocorra. Atribuímos esse papel à pulsão invocante, que se refere à pulsionalização da voz enquanto objeto, e interrogamos: como se dá o processo pelo qual o sujeito é capturado, invocado e levado a adentrar no universo simbólico?

\section{A pulsão invocante}

assujeitamento do bebê em relação ao Outro Catão (2009) mostra, em seu trabalho, o quanto o não estabelecimento da voz como objeto pulsional é paradigmático para compreender a relação da criança com o som: "Quando algo não funciona no estabelecimento do laço, resta a tentativa de tapar os ouvidos ao que não pode passar à voz, permanecendo, então, como barulho. Embora não escute, a criança autista não é surda" (p. 113). O laço a que a autora se refere

22 Estilos clin., São Paulo, v. 22, n. 1, jan./abr. 2017, 12-28. 
é a relação com o Outro, que, a princípio encarnado na figura materna, é o que dá sustento para que a criança possa existir como falante, na medida em que é antecedida e traduzida nas vocalizações maternas. Catão (2009) destaca, ainda, uma falha na passagem do som à voz, que faz que esta não funcione como objeto da pulsão e possa, então, conjugar-se à linguagem, ou seja, a voz não se instala como função psíquica.

Laznik (2004) traz a ideia da voz, ou melhor, dos picos prosódicos, como o primeiro objeto da pulsão oral. A autora apoia sua noção nas proposições freudianas acerca da alucinação, da qual se entende que as experiências de satisfação deixam marcas mnêmicas que podem ser alucinadas posteriormente diante de uma urgência. Entretanto, essas marcas, antes entendidas a partir do apoio da pulsão entre o biológico e o psíquico, passam a ser compreendidas, depois da releitura que Lacan faz do texto freudiano, como um conceito que articula o significante e o corpo. Isso denota que a satisfação da pulsão não visa a um objeto de necessidade, mas a um objeto que a cause, o qual permita que ela percorra o circuito pulsional diversas vezes. Ora, pensar o momento da primeira satisfação, com a primazia da voz sobre o alimento, explica que as marcas deixadas, enquanto traços mnêmicos, são marcas, sobretudo, do gozo materno ao se relacionar com o bebê, marcas que registram os picos prosódicos característicos do manhês. Laznik (2004) fundamenta seu entendimento também nas pesquisas dos psicolinguistas, os quais mostram os efeitos que esse modo particular de fala, caracterizado por uma gramática, pontuação, escansão e prosódia especiais, produzem na apetência oral do recém-nascido. Logo, para além do alimento, ele está em busca de palavras alimentadoras, ou, ainda, do gozo materno.

Laznik, Maestro, Muratori e Parlato-Oliveira (2006) mostram, em um estudo sobre a voz e os sinais precoces do autismo, a importância da prosódia, própria ao manhês, para a pulsionalização do ato de escuta do bebê e, inclusive, para sustentar uma "protoconversa" com o cuidador. $\mathrm{Na}$ ocasião da pesquisa, os autores comparam, a partir de vídeos familiares, as vozes das pessoas que estavam em torno dos bebês em situações cotidianas, bem como a reação dos bebês no ato de escuta. Vale ressaltar que algumas dessas crianças, posteriormente, foram diagnosticadas com autismo. O curioso foi observar que, mesmo nas crianças que se tornaram autistas e pouco respondiam às demandas dos pais, em alguns momentos, escutando a voz de um tio, por exemplo, conseguiam ser fisgadas e sustentavam o olhar numa relação com o outro. $\mathrm{Na}$ análise comparativa das vozes, verificou-se, no caso específico dessa criança, que a voz da mãe não alcançava picos prosódicos, embora a vOz do tio tenha alcançado. Isso não quer dizer, segundo os autores, que o papel dessa voz prosódica é único, afinal, 
mesmo quando fisgado pelo tio, a criança em questão não provocou, em nenhum momento, seu interlocutor, atestando a falta do terceiro tempo do circuito pulsional.

Num outro caso estudado, observou-se que, em vários momentos, a mãe conseguia fisgar seu bebê com sua prosódia, mas não conseguia falar por ele, traduzi-lo, supor um diálogo. Essa possibilidade de sustentar o diálogo, segundo os autores, é uma rude prova para uma mãe cujo bebê não lhe responde. Entretanto, o mais interessante foi observar que, em todos os bebês que posteriormente se tornaram autistas, faltava o terceiro tempo do circuito pulsional, o momento de provocar o cuidador, de conseguir sustentar um diálogo, ainda que por balbucios traduzidos como tentativa de comunicação.

Sobre a pulsão invocante, é válido marcar que, quando se fala em invocação, há a suposição de uma alteridade. A mãe supõe alteridade quando fala com o seu bebê, mas, antes de haver alteridade, o bebê é atraído pela fala melódica e prosódica de sua mãe, dirigida a ele (Catão, 2009). Julieta Jerusalinsky (2011) destaca que a musicalidade presente na voz materna, os picos prosódicos, produzem uma erotização no ato da escuta e da fonação, logo "o bebê, se é efetivamente convocado por essa voz, dirige o seu olhar à mãe, respondendo com uma excitação psicomotora ampla" (Jerusalinsky, 2011, p. 68). A autora destaca, ainda, que essa fala materna é acompanhada por uma rica expressão

24 Estilos clin., São Paulo, v. 22, n. 1, jan./abr. 2017, 12-28. 
facial, que convoca o bebê não apenas a ouvi-la, mas também a olhá-la. Nesse diálogo, a mãe, por vezes, silencia, sustentando, assim, uma matriz dialógica, na qual, nessas brechas, o bebê produzirá suas vocalizações. Nesse momento, ainda que o bebê não tenha condições de entender o sentido do que lhe é falado, ele começa a ser pulsionalizado e erotizado pela voz e, aos poucos, vai sendo tomado pelo funcionamento da linguagem.

Segundo Jerusalinsky (2011), a mãe, ao tomar as fonações do bebê como um chamado, dá voz a ele. Ela precisa entender, em cada fonação, algo que o bebê quer comunicar, e ao perguntar "que foi?" ao seu bebê, ela precisa interrogar-se a respeito do enigma do desejo que ela supõe para ele. Sobre isso, a autora destaca:

É preciso que a vocalização, enquanto puro objeto acústico, caia, seja recalcada, para ganhar um sentido enigmático e ser tomada na dimensão de um chamado no laço com o outro. É justamente a partir da instauração de um enigma do desejo que a criança se tornará falante na tentativa de a ele responder (Jerusalinsky, 2011, p. 69).

Vale ressaltar que a fala materna só tem efeito constituinte na medida em que introduz articulações simbólicas sobre o que se passa no corpo real do bebê, produzindo uma construção imaginária de um corpo do qual ele poderá apropriar-se.

O surgimento das vocalizações do bebê, segundo Catão (2009), corresponde ao investimento libidinal da voz enquanto objeto da pulsão. Ela refere que, para o sujeito poder advir na linguagem, é preciso, entretanto, que o bebê descubra o furo real da privação materna, que o traumatiza em função dele ainda não dispor da fala como recurso para simbolizar o trauma. Isso acontece no segundo tempo do circuito pulsional, quando o bebê começa a demandar da mãe-e, em suas demandas chorosas, passa a se ouvir. Para superar o traumatismo, no terceiro tempo, o bebê terá que receber um significante, cujo poder não é o mesmo da música, a qual, por meio do ritmo, faz pulsar presença-ausência, mas não é capaz de simbolizar a ausência encarnada na privação materna. Esse significante precisará dar conta da ausência na presença de um corpo, e a sonoridade deverá subir ao estatuto de voz.

Nesse sentido, fazer-se ouvir pela mãe denota a dimensão alienante do terceiro tempo do circuito pulsional, na medida em que este só poderá advir enquanto assujeitamento do bebê em relação ao Outro. ${ }^{2}$

\section{Conclusão}

Tento em vista os pontos abordados ao longo deste artigo, podemos perceber a importância de refletir sobre a constituição do sujeito para pensar a clínica do autismo e seus possíveis direcionamentos. Os autores que abordamos, sustentados pelo ensino 
de Lacan, situam a constituição do sujeito a partir da estrutura de linguagem, via pela qual é possível estabelecer uma clínica que priorize a singularidade de cada caso, cabendo ao analista tornar objeto de escuta uma fala que, muitas vezes, apresenta-se por manifestações verbais e motoras, como sons, gritos e agitações, não endereçadas a um outro. Lacan, com a noção de estruturação do inconsciente como linguagem, assinala a importância do Outro nesse processo, na medida em que é a partir dos cuidados materno-infantis que a linguagem pulsionaliza o corpo do bebê. Nesse sentido, enfatizamos, ainda, (1) o lugar dos circuitos, que permitem ao bebê fažr-se em relação ao Outro, alçando-se ao terceiro tempo do circuito pulsional, e (2) o papel da voz nesse processo estruturante que é o de advir ao universo da linguagem.

\title{
AUTISM: A MODE OF PRESENTATION OF THE SUBJECT ON LANGUAGE STRUCTURE
}

\begin{abstract}
This article aims to make a literature review of authors who study autism in a Lacanian perspective, emphasizing the notion of the structured unconsciousness as language, as well as key aspects to contemplate the constitution of the subject and a possible failure in this process, which would occur in autistic children, such as the significant inscription, the subject-Other relationship and the pulsional registries, pointing to the invocatory drive circuit as primacy.
\end{abstract}

Index terms: autism; psychoanalysis; drive invoking; constitution of the subject; voice.

\section{AUTISMO: UN MODO DE PRESENTACIÓN DEL SUJETO EN LA ESTRUCTURA DEL LENGUAJE}

\section{RESUMEN}

En este artículo se pretende hacer una revisión de la literatura en trabajos que estudian el autismo desde una perspectiva lacaniana, haciendo bincapié en la noción de lo inconsciente estructurado como un lenguaje y en aspectos clave para pensar la constitución del sujeto y un posible fallo en este proceso, que producen los niños autistas, como el registro significativo, la relación sujeto-Otro y los registros pulsionales que señalan la unidad de invocación como primacía.

Palabras clave: autismo; psicoanálisis; pulsión de la invocación; constitución del sujeto; voz:

\section{REFERÊNCIAS}

Bastos, M. B. (2012). Incidências do educar no tratar: desafios para a clínica psicanalitica da psicose e do autismo. Tese de Doutorado, Instituto de Psicologia, Universidade de São Paulo, São Paulo, SP.

26 Estilos clin., São Paulo, v. 22, n. 1, jan./abr. 2017, 12-28. 
Bernardino, L. M. F. (2011). A questão da psicose da infância, seu diagnóstico e tratamento frente ao seu "desaparecimento" da nosografia atual. In A. Jerusalinsky, \& S. Fendrik (Orgs.), O livro negro da psicopatologia contemporânea (pp. 205217). São Paulo, SP: Via Lettera.

Catão, I. (2009). O bebê nasce pela boca: voz, sujeito e clínica do autismo. São Paulo, SP: Instituto Langage.

Freud, S. (1990). Carta 52 a Fliess. In S. Freud, Edição standard brasileira das obras psicológicas completas de Sigmund Freud (J. Salomão, trad., Vol. 1, pp. 281-287). Rio de Janeiro, RJ: Imago. (Trabalho original publicado em 1895)

Freud, S. (2010). Os instintos e seus destinos. In S. Freud, Obras completas (P. C. Souza, trad., Vol. 12, pp. 51-81). São Paulo, SP: Companhia das Letras. (Trabalho original publicado em 1915)

Freud, S. (2001). A interpretação dos sonhos. Rio de Janeiro, RJ: Imago. (Trabalho original publicado em 1900)

Jerusalinsky, A. (2012). Psicanálise do autismo. São Paulo, SP: Instituto Langage.

Jerusalinsky, J. (2011). A criação da criança: brincar, gozo e fala entre a mãe e o bebê. Salvador, BA: Ágalma.

Kupfer, M. C. (2000). Notas sobre o diagnóstico diferencial da psicose e do autismo na infância. Psicologia USP, 11(1), 85-105. Recuperado de: https://dx.doi. org/10.1590/S0103-65642000000100006

Lacan, J. (1998). O estádio do espelho como formador da função do eu. In J. Lacan, Escritos (V. Ribeiro, trad., pp. 96-103). Rio de Janeiro, RJ: Zahar. (Trabalho original publicado em 1949)

Lacan, J. (1998). Posição do inconsciente. In J. Lacan, Escritos (V. Ribeiro, trad., pp. 843-864). Rio de Janeiro, RJ: Jorge Zahar. (Trabalho original publicado em 1960)

Lacan, J. (1998). Conferência em Genebra sobre o sintoma. Opção Lacaniana, 23, 6-16.

Lacan, J. (2008). O seminário, livro 11: os quatro conceitos fundamentais da psicanálise (M. D. Magno, trad.). Rio de Janeiro, RJ: Jorge Zahar. (Trabalho original publicado em 1964)

Laznik, M.-C. (2004). Do fracasso da instauração da imagem do corpo ao fracasso da instauração do circuito pulsional: quando a alienação faz falta. In M.-C. Laznik, A voz da sereia: o autismo e os impasses na constituição do sujeito (pp. 4968). Salvador, BA: Ágalma.

Laznik, M.-C., Maestro, S., Muratori, F., \& Parlato-Oliveira, E. (2006). Interaçóes sonoras entre bebês que se tornaram autistas e seus pais. In L. M. F. Bernardino (Org.), O que a psicanálise pode ensinar sobre a criança, sujeito em constituição (pp. 96-106). São Paulo, SP: Escuta.

Maleval, J.-C. (2007). "Sobretudo verbosos" os autistas. Latusa: objetos soletrados no corpo, 12, 69-91.

Nominé, B. (2012). O que nos ensinam os autistas. A peste, 4(2), 27-39.

Poizat, M. (1996). La voix sourde. Paris: Métailié.

Porge, E. (2014). Voz do eco. Campinas, SP: Mercado de Letras.

Rocha, F. H. (2009). Questões sobre a alteridade no autismo infantil. Estilos da Clinica, 14(27), 150-171. doi: http://dx.doi.org/10.11606/issn.1981-1624. v14i27p150-171 
Rodriguez, L. (1999). O dizer autista. In S. Alberti (Org.), Autismo e esquizofrenia na clínica da esquize (pp. 245-257). Rio de Janeiro, RJ: Marca d'Água.

Soler, C. (2007). O inconsciente a céu aberto na psicose. Rio de Janeiro, RJ: Jorge Zahar.

Vivès, J.-M. (2012). A voz na clínica psicanalítica. Rio de Janeiro, RJ: Contra Capa.

Vorcaro, A. (2011). O efeito bumerangue das classificaçôes psicopatológicas da infância. In A. Jerusalinsky, \& S. Fendrik (Orgs.), O livro negro da psicopatologia contemporânea (pp. 219-230). São Paulo, SP: Via Lettera.

Vorcaro, A., \& Lucero, A. (2010). Entre real, simbólico e imaginário: leituras do autismo. Psicologia e Argumento, 28(61), 147-157.

\section{NOTAS}

1. Aqui, a referência é aos objetos pulsionais freudianos, mas vale ressaltar que, quando Lacan conceitua o objeto $a$ no Seminário 10 , o falo não é incluso.

2. Consideramos importante marcar que vários autores possuem contribuiçóes fundamentais acerca da pulsão invocante, dos quais destacamos Poizat (1996), Porge (2014) e Vivès (2012). Entretanto, tendo em vista os limites deste artigo, julgamos a necessidade da produção de outro trabalho para aprofundar as demais referências sobre esta temática.

marcelaazevedo@live.com Av. Governador José Malcher, 2.088/501 66060-230 - Belém - PA - Brasil.

rf-nicolau@uol.com.br Rua dos Mundurucus, 1.553/501 66035-360 - Belém - PA - Brasil. 